\title{
Performance Evaluation of Glass-Epoxy-TiC Hybrid Composites Using Design of Experiment
}

\author{
Sangita Mohapatra, ${ }^{1}$ Sisir Mantry, ${ }^{2}$ and S. K. Singh ${ }^{1}$ \\ ${ }^{1}$ CSIR-Institute of Minerals and Materials Technology, Bhubaneswar, Odisha 751013, India \\ ${ }^{2}$ Surface Engineering Department, CSIR-Institute of Minerals and Materials Technology, Bhubaneswar 751013, India \\ Correspondence should be addressed to Sisir Mantry; mantrysisir@gmail.com
}

Received 29 October 2013; Accepted 30 December 2013; Published 9 February 2014

Academic Editor: Suying Wei

Copyright (c) 2014 Sangita Mohapatra et al. This is an open access article distributed under the Creative Commons Attribution License, which permits unrestricted use, distribution, and reproduction in any medium, provided the original work is properly cited.

\begin{abstract}
The present paper reports the processing and solid particle erosion behavior of a multiphase composite consisting of epoxy resin reinforced with E-glass fiber and TiC particles. The TiC powder synthesized from ilmenite employing DC extended thermal plasma technique has been used as the filler in these glass epoxy composites. It is observed that with increasing percentage of filler particles, there is significant improvement in hardness and erosion wear performance. It is also observed that, among all the factors, impact velocity is the most significant factor followed by TiC percentage and impingement angle, while erodent size has the least significance on erosion of the reinforced composite. Taguchi's orthogonal arrays have been used to identify the controlling factors influencing the erosion wear rate.
\end{abstract}

\section{Introduction}

Nowadays much attention is focused on the study of solid particle erosion behavior of fiber reinforced polymer composites. This is due to the high potential use of these materials in mechanical and structural applications in automobile, marine, and aerospace industries. Hence erosion resistance of polymer composites has become an important material property, particularly in selection of alternative materials.

Polymer composites are often used as engineering as well as structural components where these are subjected to wear. Wear is damage to a solid surface usually involving progressive loss of materials, owing to relative motion between the surface and a contacting surface or substances [1]. Several investigations on friction and wear properties of PEEK and its composites filled with fibers, organic and inorganic fillers have been carried out $[2,3]$. Yen and Dharan [4] have investigated the abrasive wear behavior of unidirectional fiber reinforced polymer composites. Chang et al. [5] have studied the tribological properties of fiber reinforced polymer composites like polyetheretherketone (PEEK) and polyetherimide (PEI). It has been observed that by incorporating filler particles into fiber-reinforced composites, synergistic effects can be achieved in the form of higher modulus and reduced material cost, yet accompanied with decreased strength and impact toughness [6-13].

Durand et al. [14] investigated wear behavior of polymerbased model composites reinforced with different particles including $\mathrm{TiC}$. $\mathrm{TiC}$ is an important nonoxide ceramics which exhibits high hardness, high strength, better wear, and corrosion resistance. These properties make the material useful in many applications such as metal forming dies, cutting tools, and wear resistant parts. So TiC has the potential to be used as a filler material in various polymer composites. Konopka et al. [15] studied abrasive wear behavior of nano and submicron size $\mathrm{TiC}$ particle reinforced polymer matrix composites. However, erosive wear behaviour of polymer composites reinforced with glass fibre and $\mathrm{TiC}$ particulate has not been adequately studied.

TiC powder is synthesized from ilmenite ore, naturally occurring iron titanate $\left(\mathrm{FeTiO}_{3}\right)$ which is abundant in nature. The particle size distribution, Scanning Electron Microscope (SEM), and Raman study of TiC powder reveal that its quality 


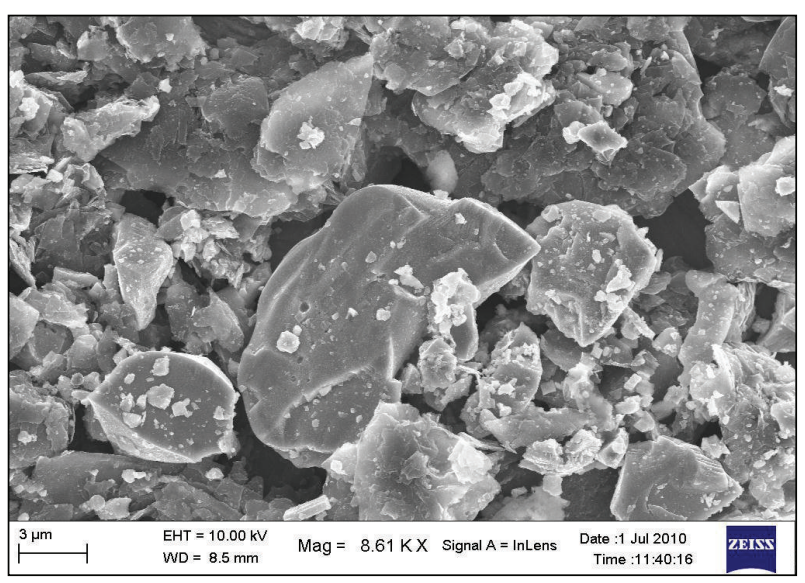

FIgURE 1: SEM micrograph of TiC powder produced.

is comparable to the commercially available $\mathrm{TiC}$ powder. So this TiC powder can be suitable filler for fabrication of low cost hybrid composites.

The objective of the present investigation is to study the effect of glass fiber reinforcement and inclusion of TiC filler on the physical and mechanical properties as well as triboperformance behavior of epoxy based composites under multiple impact conditions. An attempt has been made to optimize the process parameters for minimum wear rate.

\section{Experimental Details}

2.1. Preparation of $\mathrm{TiC}$ Powder from Ilmenite by Thermal Plasma. Ilmenite is one of the important ores of titanium. In the present investigation, $\mathrm{TiC}$ powder has been synthesized from the ilmenite concentrate by an indigenously developed extended arc plasma reactor. The reactor is a pot type reactor where graphite electrodes are arranged in a vertical configuration. The top graphite electrode is having an axial hole through which the plasma forming gas is introduced to the reactor hearth. The graphite crucible (anode) serves as the reactor hearth. The crucible is thermally insulated by bubble alumina in mild steel casing. The power to the reactor is supplied by a DC thyristor controlled power source. The detail of the reactor is described elsewhere [16].

The raw materials used here are ilmenite concentrate and activated carbon. The ilmenite concentrate after grinding to very fine size is mixed with activated carbon homogeneously. The homogeneous mixture is then peletilized and dried. In a typical plasma experiment, the flow of argon gas was regulated at $1.0 \mathrm{~L} / \mathrm{min}$. The arc voltage and current were maintained at $50 \mathrm{~V}$ and $300 \mathrm{~A}$, respectively. The overall process of the carbothermal reduction of ilmenite $\left(\mathrm{FeTiO}_{3}\right)$ with carbon in argon thermal plasma resulted in the formation of Fe-TiC composite. The product was crushed to fine size and leached with $\mathrm{HCl}$ to remove $\mathrm{Fe}$ from the $\mathrm{Fe}-\mathrm{TiC}$ composite. During leaching, the solid to liquid ratio is maintained at $1: 10$ and the strength of the acid $(\mathrm{HCl})$ was $2 / 4 \mathrm{~N}$. The temperature of the solution during leaching was approximately $100^{\circ} \mathrm{C}$. The $\mathrm{TiC}$ powder thus prepared has been characterized by XRD

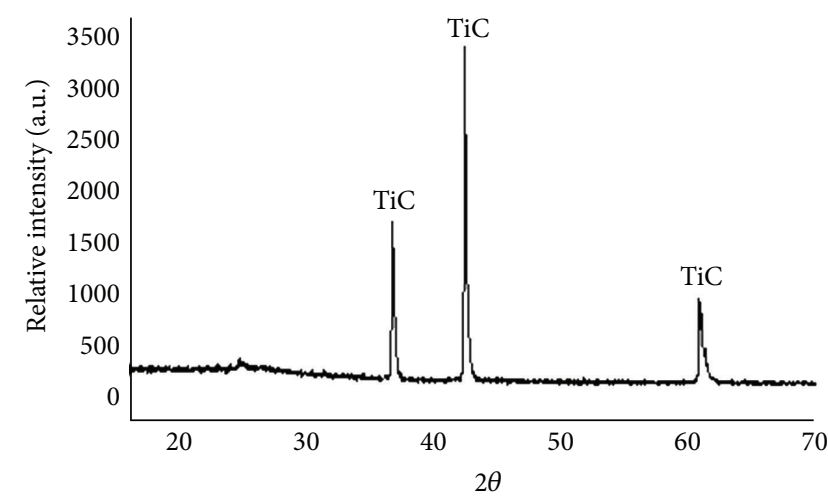

Figure 2: XRD results of TiC powder.

and SEM (FESEM Zeiss, Supra-55). The microstructure and $\mathrm{XRD}$ analysis of $\mathrm{TiC}$ power produced from ilmenite is shown in Figures 1 and 2, respectively.

2.2. Fabrication of Composites. The titanium carbide (TiC) reinforced hybrid composites were prepared by hand layup technique followed by light compression moulding using epoxy resin as the matrix material and woven E-glass fibers as the reinforcement. The epoxy resin and the hardener (HY951) are supplied by Ciba Geigy India Ltd. where the woven E-glass fibers are supplied by Saint Goblin Ltd., India. The particulate fillers $\mathrm{TiC}$ with particle size $12 \mu \mathrm{m}$ or less prepared by thermal plasma varies as $0,10,15$, and $20 \mathrm{wt} \%$ but with fixed glass-fiber loading (50 wt\%) used in the composite fabrication. First, epoxy is mixed with hardener in the ratio of $10: 1$ by weight. Then the particle fillers are mixed thoroughly in the resin before reinforcement of the fiber materials into the matrix body. Silicon spray facilitates easy removal of the composite from the mould after curing as a releasing agent. A diamond cutter has been used for cutting test samples of suitable dimensions. Utmost care has been taken to maintain uniformity and homogeneity of the composite.

2.3. Density and Void Fraction. The theoretical density of composite materials in terms of weight fraction can easily be obtained as for the following equations given by Agarwal and Broutman [18]:

$$
\rho_{c t}=\frac{1}{\left(W_{f} / \rho_{f}\right)+\left(W_{m} / \rho_{m}\right)},
$$

where $W$ and $\rho$ represent the weight fraction and density respectively. The suffixes $f, m$, and $c t$ stand for the fiber, matrix and the composite materials, respectively.

The composites under this investigation consist of three components, namely, matrix, fiber, and particulate filler. Hence the modified form of the expression for the density of the composite can be written as

$$
\rho_{c t}=\frac{1}{\left(W_{f} / \rho_{f}\right)+\left(W_{m} / \rho_{m}\right)+\left(W_{p} / \rho_{p}\right)},
$$

where the suffix " $p$ " indicates the particulate filler materials. 


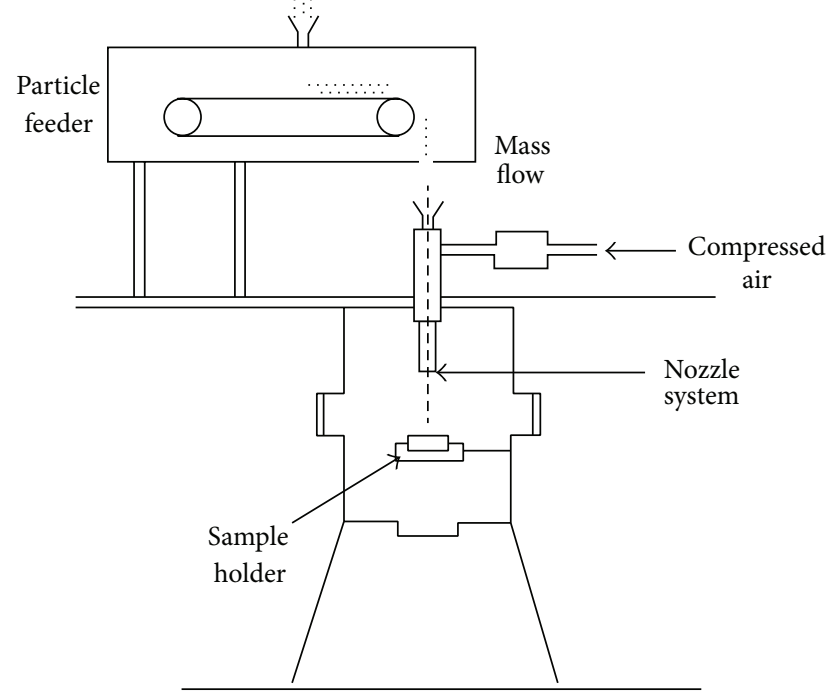

FIGURE 3: Schematic diagram of the erosion rig [17].

The actual density $\left(\rho_{c e}\right)$ of the composite, however, can be determined experimentally by simple water immersion technique. The volume fraction of voids $\left(V_{v}\right)$ in the composites is calculated using the following equation:

$$
V_{v}=\frac{\rho_{c t}-\rho_{c e}}{\rho_{c t}}
$$

2.4. Test of Microhardness. A Leco micro hardness tester is used for measurement of micro hardness. A diamond indenter in the form of a right pyramid with a square base and an angle $136^{\circ}$ between opposite faces has been used in this tester. This indenter is forced into the material under a load $F$. In the present study, the load considered $F=0.5 \mathrm{~N}$. The indentation left on the surface of the material after removal of the load has two diagonals $X$ and $Y$. These diagonals are measured and their arithmetic mean $L$ is calculated. The Vickers hardness number is calculated using the following equation:

$$
\begin{aligned}
H_{v} & =0.1889 \frac{F}{L^{2}}, \\
L & =\frac{X+Y}{2}
\end{aligned}
$$

where $F$ is the applied load $(\mathrm{N}), L$ is the diagonal of square impression ( $\mathrm{mm}), X$ is the horizontal length $(\mathrm{mm})$, and $Y$ is the vertical length $(\mathrm{mm})$.

2.5. Erosion Test. The schematic diagram of erosion test rig confirming to ASTM G 76 has been shown in Figure 3 [17]. The setup consisting of an air compressor, an air particle mixing chamber, and an accelerating chamber is capable of creating reproducible erosive situations for assessing erosion wear resistance of the prepared composite samples. The particles are mixed with dry compressed air and the mixture is fed at a constant rate from a sand flow control knob through the nozzle tube. There is a convergent brass nozzle of $3 \mathrm{~mm}$ internal diameter through which when the mixture is passed, the particles get accelerated. These particles impact the specimen which can be held at different angles with respect to the direction of erodent flow using a swivel and an adjustable sample clip. Standard double disc method is used for determining the velocity of the eroding particles [19]. Dry aluminum oxide (spherical) of different particle sizes (50, 100,200 , and $300 \mu \mathrm{m}$ ) is used as erodent in the present study. Acetone is used for cleaning the samples, and then they are dried and weighed using a precision electronic balance to an accuracy of $\pm 0.1 \mathrm{mg}$ before and after the erosion trials. Erosion rate is calculated by using the weight loss recorded.

2.6. Taguchi Experimental Design. Every single discipline has researchers carrying out experiments to observe and understand a certain process or to discover the interaction and effect of different variables. From a scientific viewpoint, these experiments are either one or a series of tests to either confirm a hypothesis or to understand a process in further detail. Experiments from a manufacturing point of view, however, are concerned with finding the optimum product and process, which is both cost effective and of a high quality. In order to achieve a meaningful end result, several experiments are usually carried out. The investigator needs to know the factors involved, the levels assigned to each factor and a method to calculate and quantify the response of each factor. This one-factor-at-a-time approach will provide the most favorable level for each factor, but not the optimum combination of all the interacting factors involved. Thus, experimentation in this scenario can be considered as an iterative process. Although it will provide a result, such methods are not time or cost effective. But the design of experiments is a scientific approach to effectively plan and perform experiments, using statistics. In such designs, the combination of each factor at every level is studied to determine the combination that would yield the best result. The advantage of such design schemes is that it will always determine the effect of factors and possible interactions (between factors) on the performance output. Taguchi design of experiment is a powerful analysis tool for modeling and analyzing the influence of control factors on performance output. Selection of the control factors is the most important stage in the design of an experiment. Exhaustive literature review on erosion behavior of polymer composites reveals that parameters, namely, impact velocity, impingement angle, fiber loading, filler content, erodent size, and so forth largely influence the erosion rate of polymer composites [20-31]. In the present work, the impact of five such parameters, namely, velocity of impact, filler percentage, impingement angle, erodent size, and erodent temperature each at four levels, are studied using $\mathrm{L}_{16}\left(4^{5}\right)$ orthogonal design. Table 1 represents the operating parameters and the selected levels. The tests are conducted as per experimental designs given in Table 2. In Table 5, each of the second to sixth columns represents a test parameter and a row gives a test condition which is nothing but combination of parameter levels. Five parameters each at four levels would require $4^{5}=1024$ runs in a full factorial 
TABLE 1: Levels of the variables used in the experiment.

\begin{tabular}{lccccc}
\hline Control factor & \multicolumn{5}{c}{ Level } \\
& I & II & III & IV & Units \\
\hline A: velocity of impact & 33 & 47 & 57 & 68 & $\mathrm{~m} / \mathrm{s}$ \\
$B$ : impingement angle & 30 & 45 & 60 & 90 & $\circ$ \\
$C:$ erodent size & 50 & 100 & 200 & 300 & $\mu \mathrm{m}$ \\
$D:$ TiC percentage & 0 & 10 & 15 & 20 & $\%$ \\
E: erodent temperature & 25 & 50 & 75 & 100 & ${ }^{\circ} \mathrm{C}$ \\
\hline
\end{tabular}

TABLE 2: Erosion test conditions.

\begin{tabular}{lcc}
\hline Sl. number & Test parameter & Type/value \\
\hline 1 & Erodent & Aluminum oxide \\
2 & Erodent size $(\mu \mathrm{m})$ & $50,100,200$ and 300 \\
3 & Erodent shape & Spherical \\
4 & Impact angle $\left({ }^{\circ}\right)$ & $30,45,60$ and 90 \\
5 & Impact velocity $(\mathrm{m} / \mathrm{s})$ & $33,47,57$ and 68 \\
6 & Erodent feed frequency $(\mathrm{Hrz})$ & 10 \\
7 & Test temperature $\left({ }^{\circ} \mathrm{C}\right)$ & $25,50,75$ and 100 \\
8 & Nozzle to sample distance $(\mathrm{mm})$ & 10 \\
\hline
\end{tabular}

experiment, whereas Taguchi's factorial experiment approach reduces it to 16 runs which is a great advantage in terms of cost and time. The second column is assigned to impact velocity $(A)$, the third column to impingement angle $(B)$, fourth column to erodent size $(C)$, the fifth column to filler loading $(D)$, and the sixth column to erodent temperature $(E)$. The experimental observations are further transformed into a signal-to-noise $(S / N)$ ratio. Depending on the type of characteristics, there are several $S / N$ ratios available:

"Smaller the better" characteristic:

$$
\frac{S}{N}=-10 \log \frac{1}{n}\left(\sum y^{2}\right) \text {. }
$$

"Nominal the better" characteristics:

$$
\frac{S}{N}=-10 \log \frac{1}{n}\left(\sum \frac{\bar{Y}}{S_{Y}^{2}}\right) .
$$

"Larger the better" characteristics:

$$
\frac{S}{N}=-10 \log \frac{1}{n}\left(\sum \frac{1}{y^{2}}\right),
$$

where $n$ is the number of observations and $y$ is the observed data. The $S / N$ ratio for minimum erosion rate coming under "smaller is better" characteristic can be calculated as logarithmic transformation of the loss function as shown in (5).

\section{Results and Discussion}

3.1. Density and Void Fraction Analysis. The theoretical and measured densities of glass-epoxy composites with $\mathrm{TiC}$ filler along with the corresponding volume fraction of voids are presented in Table 3. It is observed that the theoretically

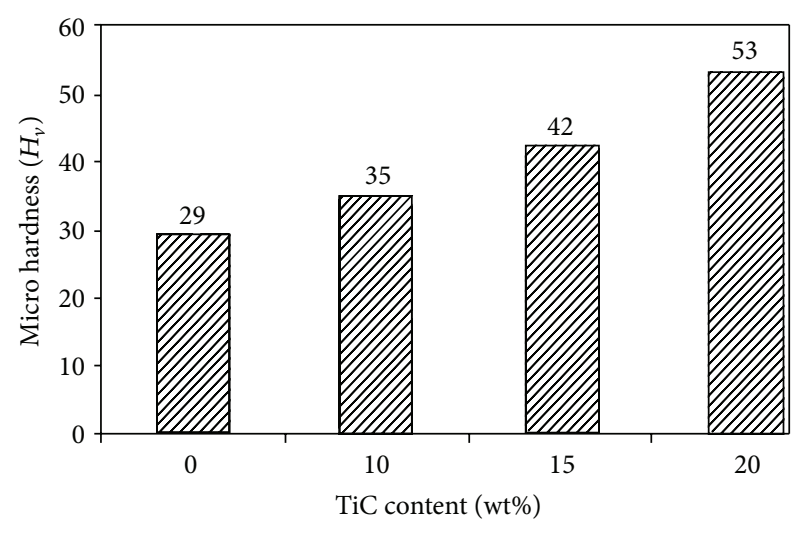

FIGURE 4: Variation of microhardness of the composites with TiC content.

calculated density values of the composites for different weight fractions using (2) are not equal to the experimentally measured values. It is evident from Table 3 that the density values for glass-epoxy composites increase with increase in filler content. The filler contains irregular particles and as the percentage increases, the void fraction increases due to improper wetting and formation of air bubbles and dissolved gases dispersion of filler into polymeric matrix. It can be reduced by proper stirring, which isnot much adequate because of hand lay-up technique.

3.2. Microhardness Study. The variation of composite microhardness with the weight fraction of $\mathrm{TiC}$ particulates is shown in Table 4.

It is seen that with the incorporation of filler particulates into the composites, the mean hardness is seen to have improved as shown in Figure 4. In hardness test, a compressive or pressing stress is in action. So the polymeric matrix phase and the solid filler phase would be pressed together and touch each other more tightly.

Thus, the interface can transfer pressure more effectively although the interfacial bond may be poor. This might have resulted in enhancement of hardness. Similar property modification has been observed in case of polyurethane matrix composite reinforced with $\mathrm{Al}_{2} \mathrm{O}_{3}$ particles [22].

3.3. Taguchi Analysis of the Erosion Test Results. The erosion wear rates of $\mathrm{TiC}$ filled glass-epoxy matrix composites under various test conditions are given in Table 5. The last columns represent $S / N$ ratio of the erosion rate, which is in fact the average of three replications. The overall mean for the $S / N$ ratio of the erosion rate is found to be $-44.2194 \mathrm{db}$ of $\mathrm{TiC}$ composites. The analysis is made using the popular software specifically used for design of experiment applications known as MINITAB 14. The graphical sketch in Figure 5 (obtained using MINITAB14 software) represents the influence of individual factor influencing erosion rate of TiC filled glass-epoxy composites in an interactive environment, that is, considering the mean of $S / N$ ratio of single control factor mentioned in corresponding iterations. Slope of each curve in the figure is a measure of the influence of that factor on the output. The 
TABLE 3: Density and volume fraction of voids.

\begin{tabular}{lccc}
\hline Composition & $\begin{array}{c}\text { Theoretical } \\
\text { density }(\mathrm{gm} / \mathrm{cc})\end{array}$ & $\begin{array}{c}\text { Measured density } \\
(\mathrm{gm} / \mathrm{cc})\end{array}$ & $\begin{array}{c}\text { Volume fraction } \\
\text { of voids }(\%)\end{array}$ \\
\hline Glass-epoxy + 0 wt\% TiC & 1.544 & 1.530 & 0.906 \\
Glass-epoxy + 10 wt\% TiC & 1.831 & 1.761 & 3.823 \\
Glass-epoxy + 15 wt\% TiC & 1.945 & 1.876 & 3.547 \\
Glass-epoxy + 20 wt\% TiC & 2.070 & 2.009 & 2.95 \\
\hline
\end{tabular}

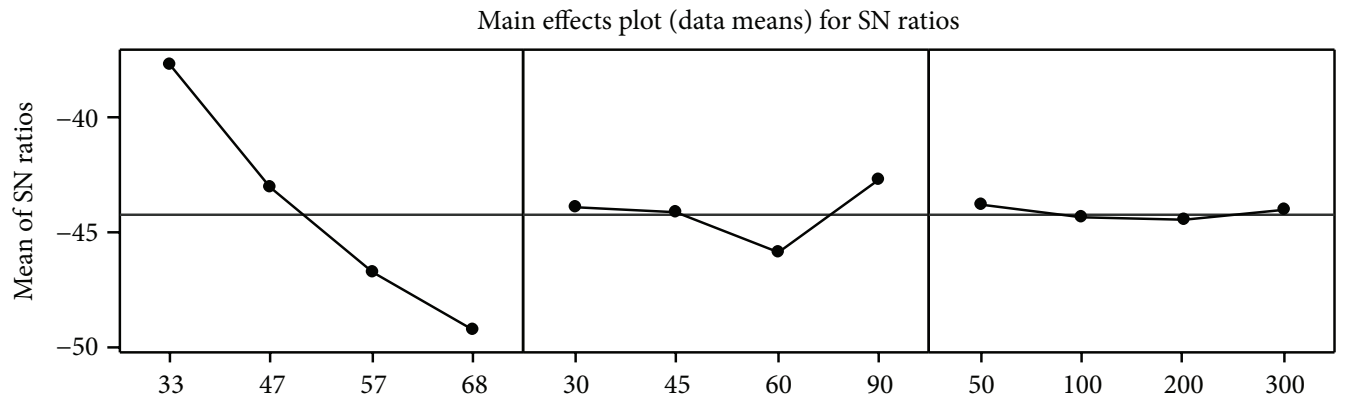

(a)

(b)

(c)

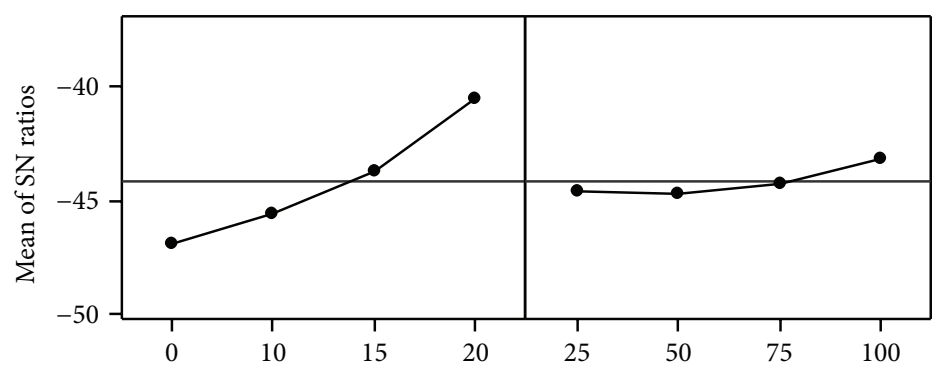

(d)

(e)

Signal-to-noise: smaller is better

FIGURE 5: Effect of control factors on erosion rate.

TABLE 4: Microhardness of polymer composites.

\begin{tabular}{lcccc}
\hline TiC in wt $\%$ & $X$ & $Y$ & $L=(X+Y) / 2$ & Micro hardness $\left(H_{v}\right)$ \\
\hline 0 & 54.2 & 59.8 & 57 & 29 \\
10 & 49.21 & 54.67 & 51.94 & 35 \\
15 & 45.52 & 49.32 & 47.42 & 42 \\
20 & 40.89 & 43.53 & 42.21 & 53 \\
\hline
\end{tabular}

$S / N$ ratio response is also given in Table 6 . From the figure and the table, it can be concluded that among all the factors, impact velocity is the most significant factor followed by $\mathrm{TiC}$ percentage and impingement angle, while the erodent size has the least significance on erosion of the reinforced composite. It also leads to the conclusion that factor combination of $A 1$, $B 4, C 1, D 4$, and $E 4$ gives minimum erosion rate.

3.4. Steady State Erosion Rate. The erosion rate of the composites is generally correlated with many operating parameters like impact velocity, impact angle, and erodent size. Angle of impingement is one of the strong factors on which the erosion rate depends. If maximum erosion takes place at

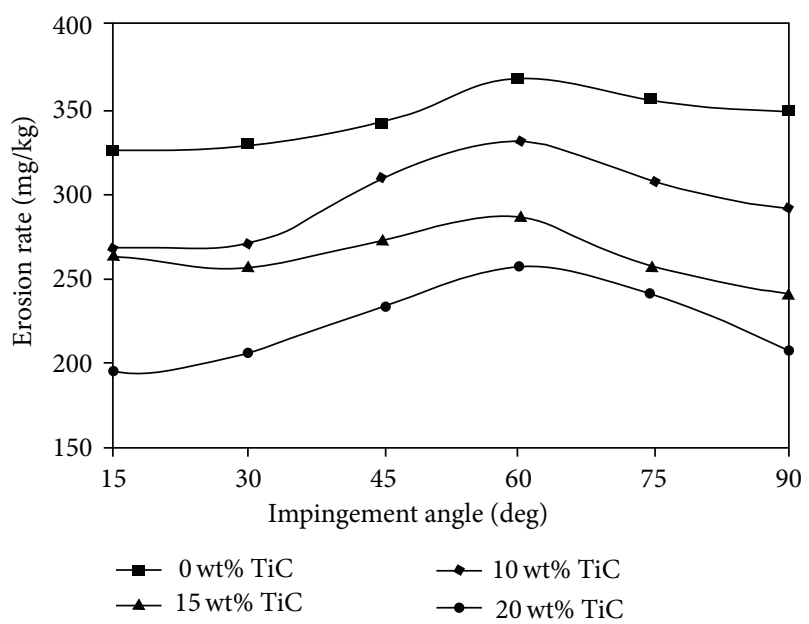

Figure 6: Effect of impingement angle on erosion rate.

$15-30^{\circ}$, it shows the ductile response of the material and if maximum erosion takes place at normal impact that is, $90^{\circ}$, 
TABLE 5: $\mathrm{L}_{16}$ Orthogonal array design with output and $S / N$ ratio.

\begin{tabular}{|c|c|c|c|c|c|c|c|}
\hline Sl. number & $\begin{array}{c}\text { Impact } \\
\text { velocity }(A) \text { in } \\
\mathrm{m} / \mathrm{s}\end{array}$ & $\begin{array}{l}\text { Impingement } \\
\text { angle }(B) \\
\text { in degree }\end{array}$ & $\begin{array}{c}\text { Erodent size } \\
\qquad(C) \\
\text { in } \mu \mathrm{m}\end{array}$ & $\begin{array}{c}\text { Filler content } \\
(D) \\
\text { in wt } \%\end{array}$ & $\begin{array}{c}\text { Erodent temp. } \\
(E) \\
\text { in }{ }^{\circ} \mathrm{C}\end{array}$ & $\begin{array}{c}\text { Erosion rate } \\
(\mathrm{Er}) \\
\text { in } \mathrm{mg} / \mathrm{kg}\end{array}$ & $S / N$ ratio in $\mathrm{db}$ \\
\hline 1 & 33 & 30 & 50 & 0 & 25 & 102.146 & -40.1844 \\
\hline 2 & 33 & 45 & 100 & 10 & 50 & 97.583 & -39.7875 \\
\hline 3 & 33 & 60 & 200 & 15 & 75 & 93.249 & -39.3929 \\
\hline 4 & 33 & 90 & 300 & 20 & 100 & 36.862 & -31.3316 \\
\hline 5 & 47 & 30 & 100 & 15 & 100 & 118.856 & -41.5004 \\
\hline 6 & 47 & 45 & 50 & 20 & 75 & 91.147 & -39.1948 \\
\hline 7 & 47 & 60 & 300 & 0 & 50 & 247.486 & -47.8710 \\
\hline 8 & 47 & 90 & 200 & 10 & 25 & 152.367 & -43.6578 \\
\hline 9 & 57 & 30 & 200 & 20 & 50 & 156.657 & -43.8990 \\
\hline 10 & 57 & 45 & 300 & 15 & 25 & 213.314 & -46.5804 \\
\hline 11 & 57 & 60 & 50 & 10 & 100 & 265.143 & -48.4696 \\
\hline 12 & 57 & 90 & 100 & 0 & 75 & 263.146 & -48.4039 \\
\hline 13 & 68 & 30 & 300 & 10 & 75 & 330.346 & -50.3794 \\
\hline 14 & 68 & 45 & 200 & 0 & 100 & 368.034 & -51.3178 \\
\hline 15 & 68 & 60 & 100 & 20 & 25 & 251.035 & -47.9947 \\
\hline 16 & 68 & 90 & 50 & 15 & 50 & 238.382 & -47.5455 \\
\hline
\end{tabular}

TABLE 6: Response table for signal-to-noise ratios.

\begin{tabular}{lccccc}
\hline Level & $A$ & $B$ & $C$ & $D$ & -46.94 \\
\hline 1 & -37.67 & -43.99 & -43.85 & -45.57 & -44.60 \\
2 & -43.06 & -44.22 & -44.42 & -43.75 & -44.78 \\
3 & -46.84 & -45.93 & -44.57 & -40.61 & -44.34 \\
4 & -49.31 & -42.73 & -44.04 & 6.34 & -43.15 \\
\hline Delta & 11.64 & 3.20 & 0.72 & $\mathbf{2}$ & $\mathbf{4}$ \\
Rank & $\mathbf{1}$ & $\mathbf{3}$ & $\mathbf{5}$ & & $\mathbf{4}$ \\
\hline
\end{tabular}

Bold font refers to the factors and their assigned ranks.

the response of the material to solid particle erosion is brittle in nature. Semiductile behaviour is characterized by the maximum erosion rate at $45-60^{\circ}$. In the present study, erosion wear rate of glass-epoxy composites filled with $\mathrm{TiC}$ particle with varying composition from $0-20 \mathrm{wt} \%$ with different angle of impingement is studied by conducting experiments under specific operating conditions (impact velocity remains constant at $68 \mathrm{~m} / \mathrm{s}$ and erodent used are of size $200 \mu \mathrm{m}$ ). The results are shown in Figure 6, which shows that the maximum erosion takes place at $60^{\circ}$ showing semiductile response to solid particle erosion. Similar semiductile behaviour of other polymer composites is also observed in many literatures [32, 33].

3.5. Surface Morphology. The surface microstructures of the uneroded and eroded composite samples are observed under SEM (FESEM Zeiss, Supra-55). As shown in Figure 7(a) the surfaces are reasonably homogeneous. No cracks are visible although some voids and pores are present. The eroded surfaces of TiC filled glass-epoxy composites subjected to different impingement angle at different impact velocities are shown in Figure 7(b)-Figure 7(f). It shows local removal of epoxy material from the impacted surface resulting in exposure of fibers to the excessive erosive environment. The morphology also reveals that due to particle impact on fibers, there is formation of transverse crack and longitudinal crack that break the fibers as shown in Figure 7(b). The propagation of both transverse and longitudinal cracks is visible across the fibers and those cracks have grown as a result of which fragmentation takes place. The damage mechanism is reflected by formation of microcracks at surface and/or subsurface regions, which finally forms wear debris. The fibres are completely broken by means of shearing action and protruding of fibers from matrix can be seen due to impingement of particles at higher impact velocity. Figure $7(\mathrm{e})$ shows the surface of $20 \% \mathrm{TiC}$ filled composite eroded at $90^{\circ}$ impingement angle at an impact velocity of $33 \mathrm{~m} / \mathrm{s}$. It is clearly visible that at minimum velocity and $90^{\circ}$ impingement angle, erosion is minimum. Figure 7(f) shows maximum erosion of $0 \%$ filled composite eroded at an angle of $45^{\circ}$ at an impact velocity $68 \mathrm{~m} / \mathrm{s}$. It is also visible from Figures $7(\mathrm{~b}), 7(\mathrm{c})$, and $7(\mathrm{~d})$ that for all the composites, the erosion rate is more at an impingement angle of $60^{\circ}$. These 


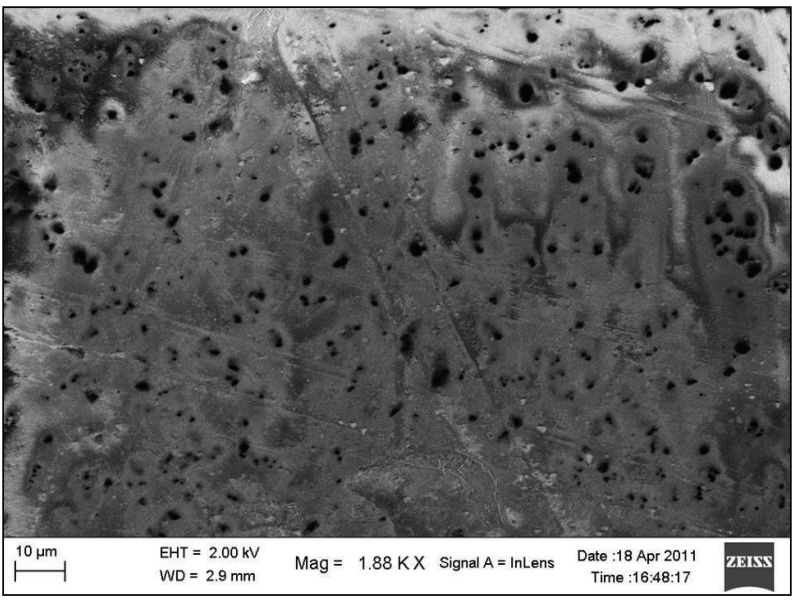

(a)

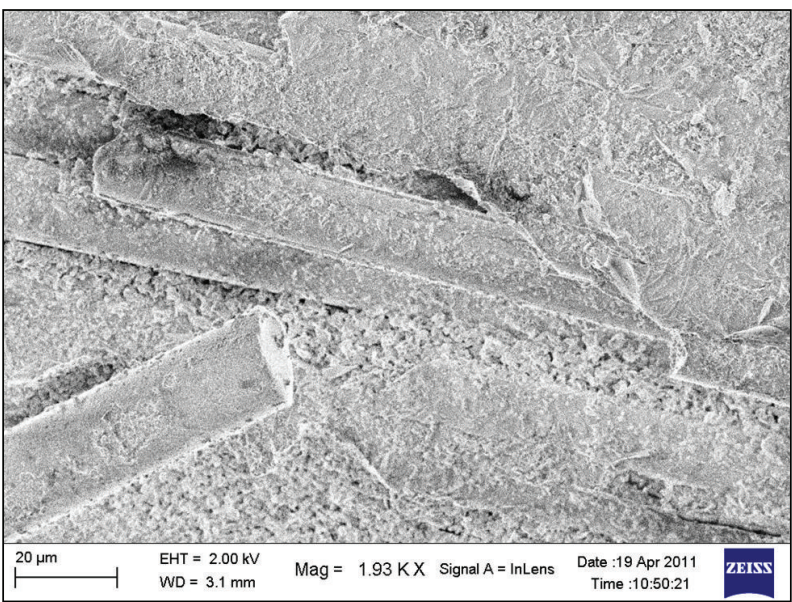

(c)

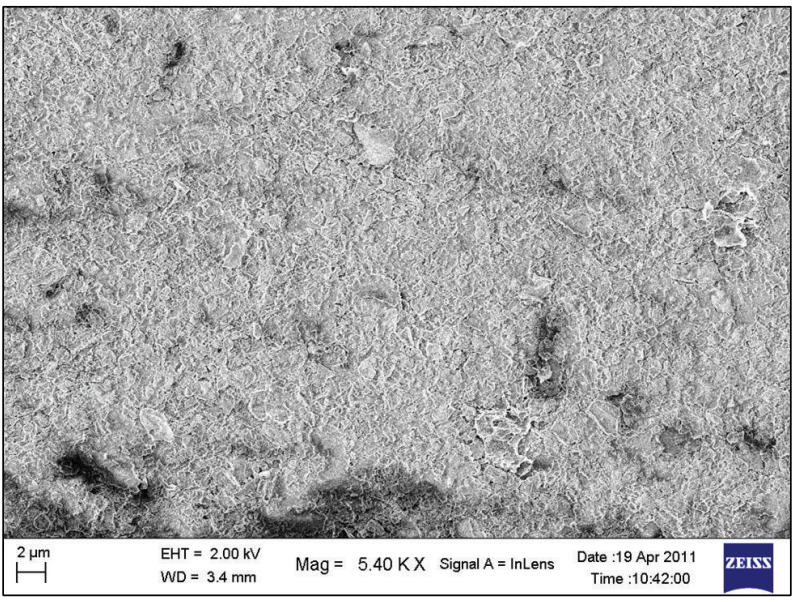

(e)

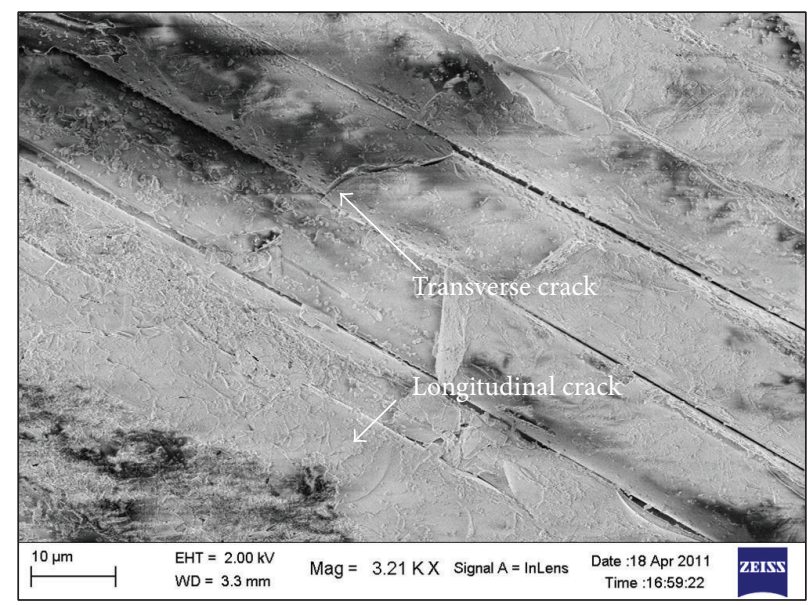

(b)

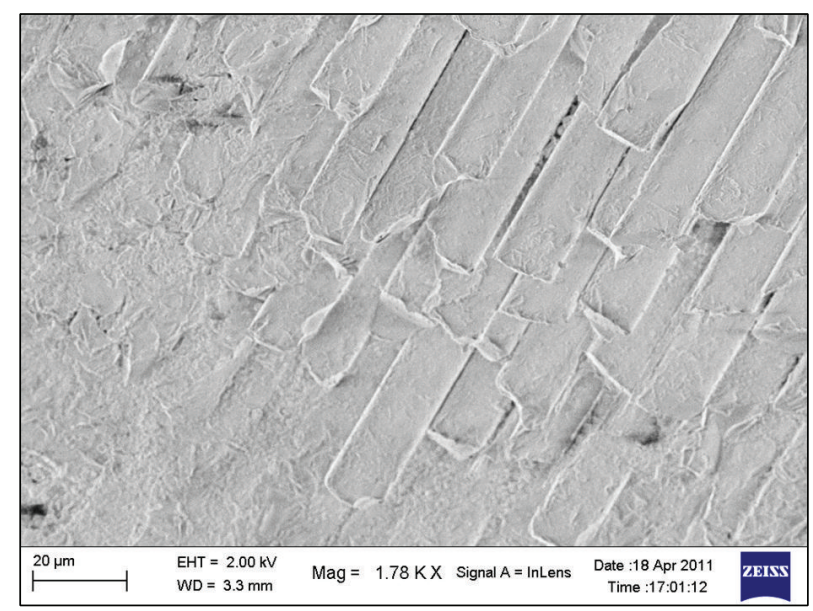

(d)

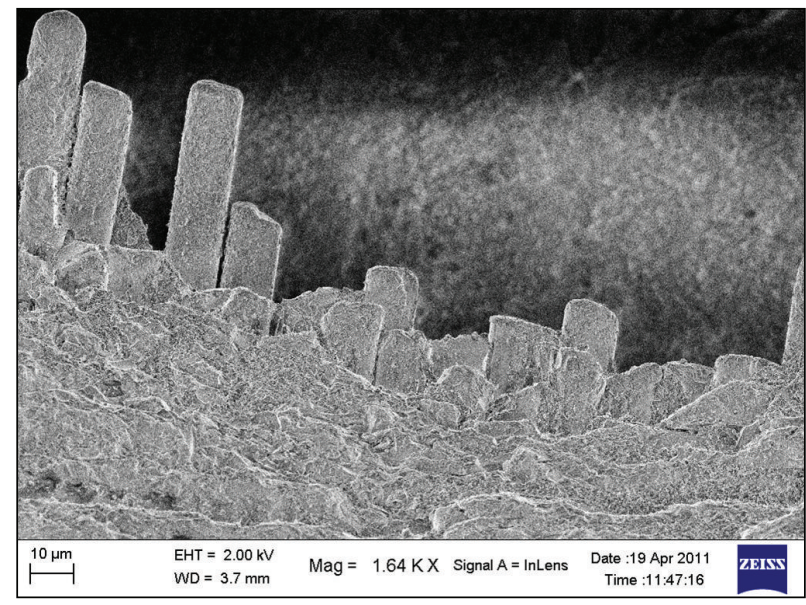

(f)

Figure 7: (a) uneroded composite. (b) $10 \%$ filled composite eroded at an impingement angle of $60^{\circ}$, impact velocity $47 \mathrm{~m} / \mathrm{s}$. (c) $15 \%$ filled composite eroded at an impingement angle of $60^{\circ}$, impact velocity $33 \mathrm{~m} / \mathrm{s}$.(d) $20 \%$ filled composite eroded at an impingement angle of $60^{\circ}$, impact velocity $57 \mathrm{~m} / \mathrm{s}$. (e) $20 \%$ filled composite eroded at an impingement angle of $90^{\circ}$, impact velocity $33 \mathrm{~m} / \mathrm{s}$. (f) $0 \%$ filled composite eroded at an impingement angle of $45^{\circ}$, impact velocity $68 \mathrm{~m} / \mathrm{s}$. 
results are in agreement with some previous observations $[28,34,35]$.

\section{Conclusions}

(i) Successful fabrication of multicomponent hybrid glass-epoxy composites with reinforcement of $\mathrm{TiC}$ prepared by plasma processing route is possible.

(ii) These composites have adequate potential for applications in highly erosive environments.

(iii) The erosion wear performance of the composites shows significant improvement with the addition of TiC filler.

(iv) The presence of particulate fillers (titanium carbide) in these composites improves their erosion wear resistance and this improvement depends on the weight content of the filler.

(v) Among all the factors, impact velocity is the most significant factor followed by $\mathrm{TiC}$ percentage and impingement angle, while the erodent size has the least significance on erosion rate.

(vi) The future investigations can be extended to newer composites using other ceramic fillers and the resulting experimental findings can be similarly analyzed.

\section{Conflict of Interests}

The authors declare that there is no conflict of interests regarding the publication of this paper.

\section{Acknowledgment}

One of the authors Mrs. Sangita Mohapatra is thankful to CSIR for granting SRF.

\section{References}

[1] A. Patnaik, A. Satapathy, N. Chand, N. M. Barkoula, and S. Biswas, "Solid particle erosion wear characteristics of fiber and particulate filled polymer composites: a review," Wear, vol. 268, no. 1, pp. 249-263, 2010.

[2] M. Cirino, R. B. Pipes, and K. Friedrich, "The abrasive wear behaviour of continuous fibre polymer composites," Journal of Materials Science, vol. 22, no. 7, pp. 2481-2492, 1987.

[3] Q. H. Wang, Q. J. Xue, W. M. Liu, and J. M. Chen, "The friction and wear characteristics of nanometer $\mathrm{SiC}$ and polytetrafluoroethylene filled polyetheretherketone," Wear, vol. 243, no. 1-2, pp. 140-146, 2000.

[4] B. K. Yen and C. K. H. Dharan, "A model for the abrasive wear of fiber-reinforced polymer composites," Wear, vol. 195, no. 1-2, pp. 123-127, 1996.

[5] L. Chang, Z. Zhang, L. Ye, and K. Friedrich, "Tribological properties of high temperature resistant polymer composites with fine particles," Tribology International, vol. 40, no. 7, pp. 1170-1178, 2007.

[6] B. Pukanszky, "Particulate filled polypropylene: structure and properties," in Polypropylene: Structure, Blends and Composites,
J. Karger-Kocsis, Ed., pp. 1-70, Chapman and Hall, London, UK, 1995.

[7] J. L. Acosta, E. Morales, M. C. Ojeda, and A. Linares, "Effect of addition of sepiolite on the mechanical properties of glass fiber reinforced polypropylene," Die Angewandte Makromolekulare Chemie, vol. 138, no. 1, pp. 103-110, 1986.

[8] X. Zhang, O. Alloul, Q. He et al., "Strengthened magnetic epoxy nanocomposites with protruding nanoparticles on the graphene nanosheets," Polymer, vol. 54, no. 14, pp. 3594-3604, 2013.

[9] X. Zhang, O. Alloul, J. Zhu et al., "Iron core carbon shell nanoparticles reinforced electrically conductive magnetic epoxy resin nanocomposites with reduced flammability," RSC Advacnes, vol. 3, pp. 9453-9464, 2013.

[10] X. Zhang, Q. He, H. Gu, S. Wei, and Z. Guo, "Polyaniline stabilized barium titanate nanoparticles reinforced epoxy nanocomposites with high dielectric permittivity and reduced flammability," Journal of Materials Chemistry C, vol. 1, pp. 28862899, 2013.

[11] X. Zhang, Q. He, H. Gu, H. A. Colorado, S. Wei, and Z. Guo, "Flame retardant electrical conductive nano-polymers based on bisphenol F epoxy resin reinforced with nano polyanilines," ACS Applied Materials \& Interfaces, vol. 5, no. 3, pp. 898-910, 2013.

[12] G. U. Hongbo, S. Tadakamalla, X. Zhang et al., "Epoxy resin nanosuspensions and reinforced nanocomposites from polyaniline stabilized multi-walled carbon nanotubes," Journal of Materials Chemistry C, vol. 1, pp. 729-743, 2013.

[13] H. Gu, J. Guo, Q. He et al., "Flame retardant epoxy resin nanocomposites reinforced with polyaniline stabilized silica nanoparticles," Industrial \& Engineering Chemistry Research, vol. 52, no. 23, pp. 7718-7728, 2013.

[14] J. M. Durand, M. Vardavoulias, and M. Jeandin, "Role of reinforcing ceramic particles in the wear behaviour of polymerbased model composites," Wear, vol. 181-183, pp. 833-839, 1995.

[15] K. Konopka, A. Biedunkiewicz, A. Boczkowska, Z. Rosłaniec, and K. J. Kurzydłowski, "Polymer matrix composites with particles of TiC obtained by a Sol-Gel method," Solid State Phenomena, vol. 106, pp. 141-144, 2005.

[16] S. K. Singh, B. C. Mohanty, and S. B. Basu, "Synthesis of SiC from rice husk in a plasma reactor," Bulletin of Materials Science, vol. 25, no. 6, pp. 561-563, 2002.

[17] S. Mantry, S. Mohapatra, S. Mohapatra, S. K. Singh, A. Mandal, and A. Satpathy, "Erosion behaviour of glass-epoxy composites filled with $\mathrm{SiC}$ from bamboo leaf," International Polymer Processing, vol. 26, no. 2, pp. 164-172, 2011.

[18] B. D. Agarwal and L. J. Broutman, Analysis and Performance of Fiber Composites, John Wiley and Sons, New York, NY, USA, 2nd edition, 1990.

[19] A. W. Ruff and L. K. Ives, "Measurement of solid particle velocity in erosive wear,” Wear, vol. 35, no. 1, pp. 195-199, 1975.

[20] A. Patnaik, A. Satapathy, S. S. Mahapatra, and R. R. Dash, "Tribo-performance of polyester hybrid composites: damage assessment and parameter optimization using Taguchi design," Materials and Design, vol. 30, no. 1, pp. 57-67, 2009.

[21] A. Patnaik, A. Satapathy, S. S. Mahapatra, and R. R. Dash, "A Taguchi approach for investigation of erosion of glass fiber-polyester composites," Journal of Reinforced Plastics and Composites, vol. 27, no. 8, pp. 871-888, 2008.

[22] A. Patnaik, A. Satapathy, S. S. Mahapatra, and R. R. Dash, "Parametric optimization erosion wear of polyester-GF-alumina 
hybrid composites using the Taguchi method," Journal of Reinforced Plastics and Composites, vol. 27, no. 10, pp. 1039-1058, 2008.

[23] A. Patnaik, A. Satapathy, S. S. Mahapatra, and R. R. Dash, "Erosive wear assesment of glass reinforced polyester-flyash composites using Taguchi method," International Polymer Processing, vol. 23, no. 2, pp. 192-199, 2008.

[24] S. S. Mahapatra, A. Patnaik, and A. Satapathy, "Taguchi method applied to parametric appraisal of erosion behavior of GFreinforced polyester composites," Wear, vol. 265, no. 1-2, pp. 214-222, 2008.

[25] A. Patnaik, A. Satapathy, S. S. Mahapatra, and R. R. Dash, "A modeling approach for prediction of erosion behavior of glass fiber-polyester composites," Journal of Polymer Research, vol. 15, no. 2, pp. 147-160, 2008.

[26] H. A. Aglan and T. A. Chenock Jr., Erosion Damage Features of Polyimide Thermoset Composites, vol. 24 of SAMPE Quarterly, 1993.

[27] A. P. Harsha, U. S. Tewari, and B. Venkatraman, "Solid particle erosion behaviour of various polyaryletherketone composites," Wear, vol. 254, no. 7-8, pp. 693-712, 2003.

[28] T. Sinmazçelik and I. Taşkiran, "Erosive wear behaviour of polyphenylenesulphide (PPS) composites," Materials and Design, vol. 28, no. 9, pp. 2471-2477, 2007.

[29] U. S. Tewari, A. P. Harsha, A. M. Häger, and K. Friedrich, "Solid particle erosion of unidirectional carbon fibre reinforced polyetheretherketone composites," Wear, vol. 252, no. 11-12, pp. 992-1000, 2002.

[30] R. Zhou, D. H. Lu, Y. H. Jiang, and Q. N. Li, "Mechanical properties and erosion wear resistance of polyurethane matrix composites," Wear, vol. 259, no. 1-6, pp. 676-683, 2005.

[31] R. Rattan and J. Bijwe, "Influence of impingement angle on solid particle erosion of carbon fabric reinforced polyetherimide composite," Wear, vol. 262, no. 5-6, pp. 568-574, 2007.

[32] S. Biswas and A. Satapathy, "Use of copper slag in glass-epoxy composites for improved wear resistance," Waste Management and Research, vol. 28, no. 7, pp. 615-625, 2010.

[33] S. Biswas and A. Satapathy, "Tribo-performance analysis of red mud filled glass-epoxy composites using Taguchi experimental design," Materials and Design, vol. 30, no. 8, pp. 2841-2853, 2009.

[34] P. K. Mishra, Non-Conventional Machining, Narosa, New Delhi, India, 1997.

[35] G. Sundararajan, M. Roy, and B. Venkataraman, "Erosion efficiency-a new parameter to characterize the dominant erosion micromechanism," Wear, vol. 140, no. 2, pp. 369-381, 1990. 

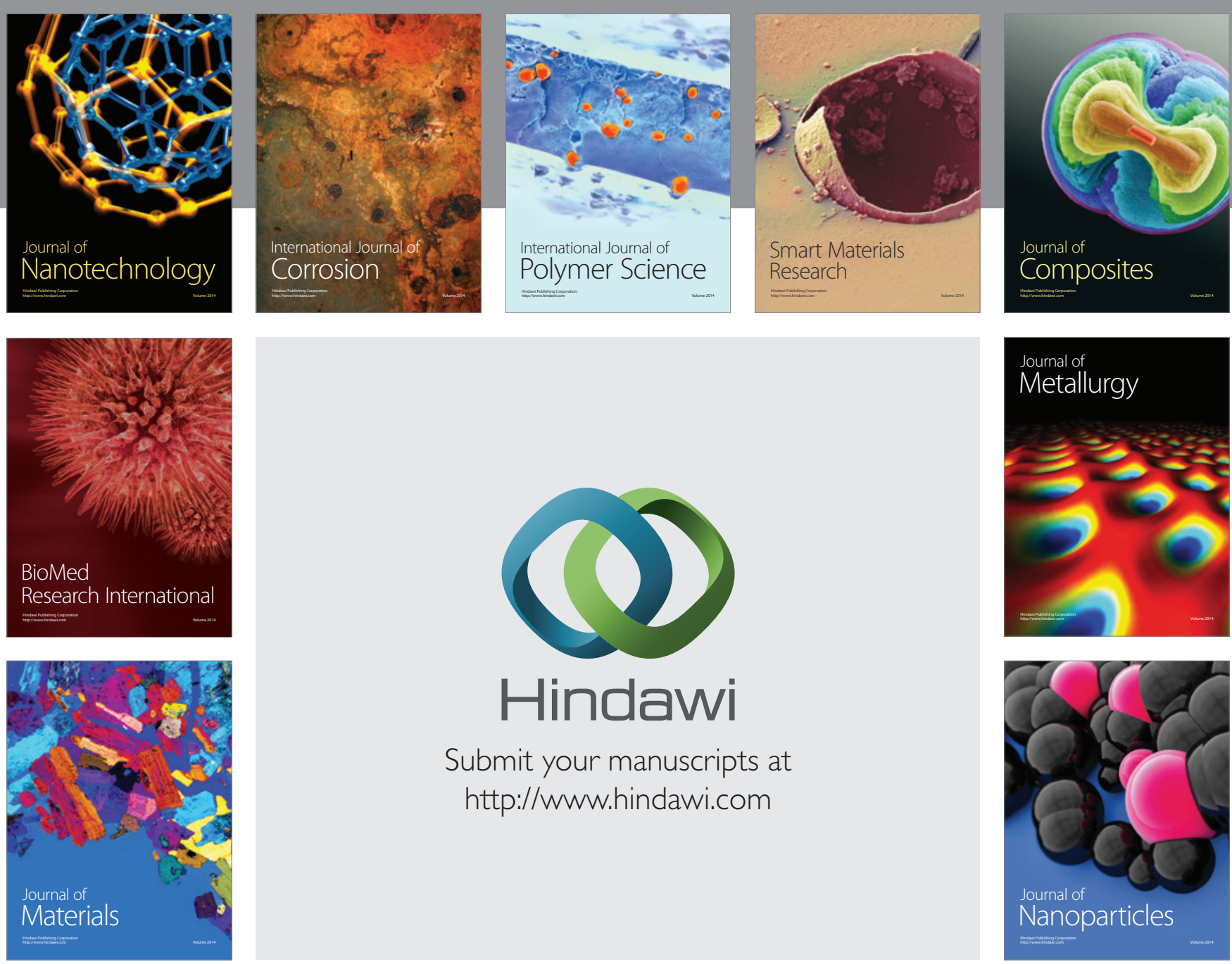

Submit your manuscripts at http://www.hindawi.com
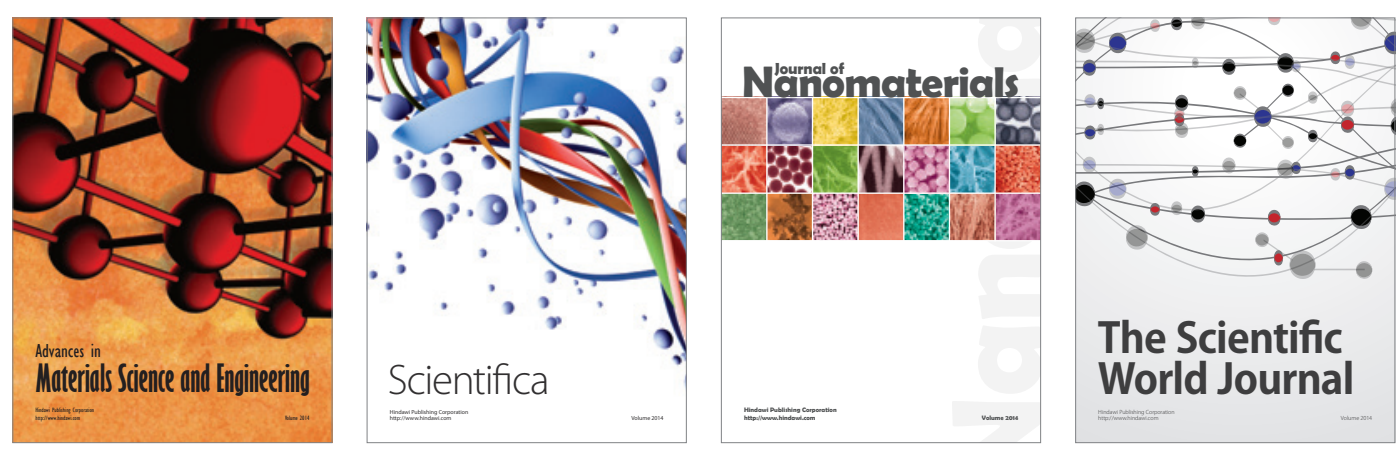

\section{The Scientific World Journal}
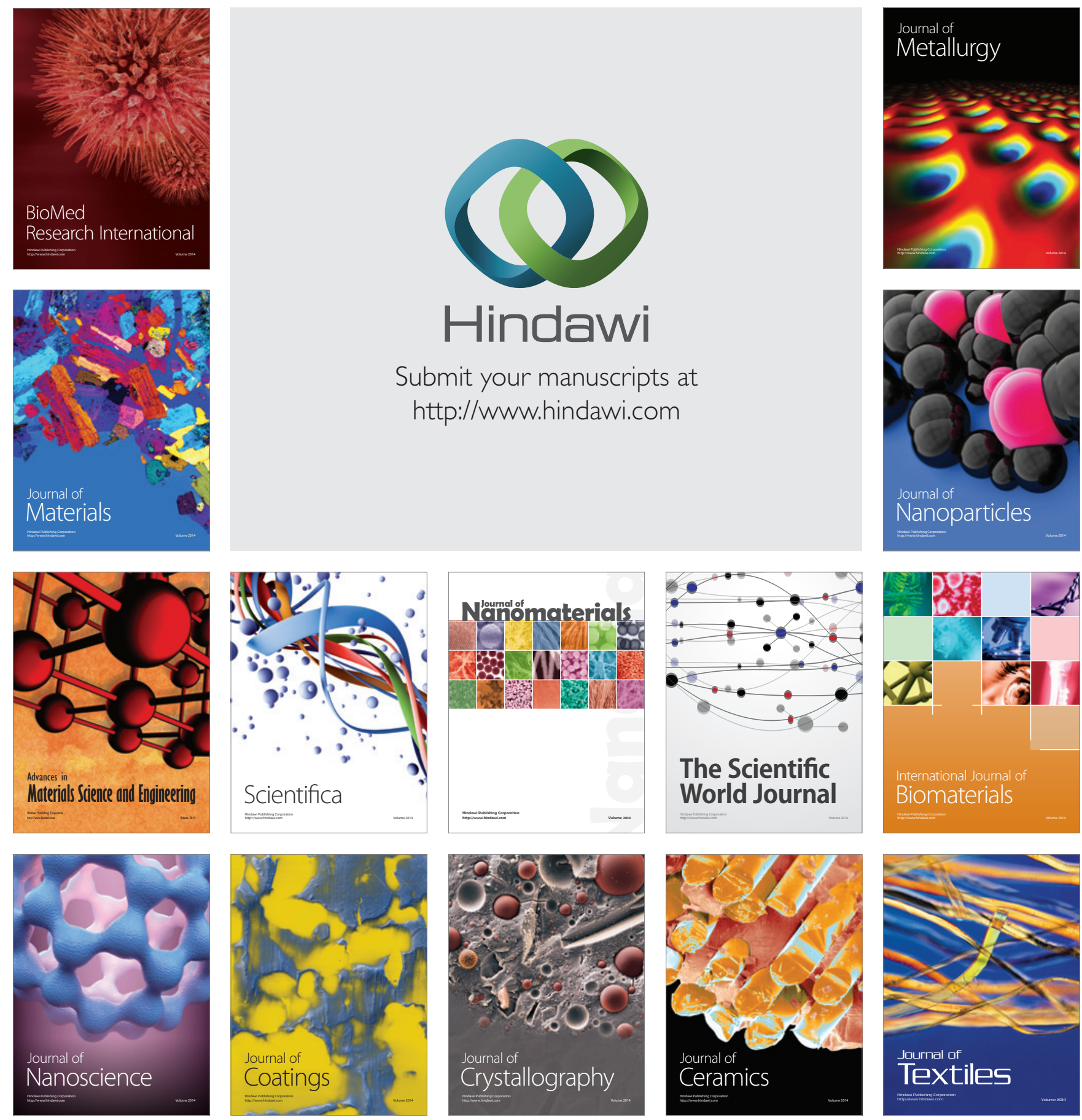